\title{
SASRAD: An hourly-timestep solar radiation database for South Africa
}

\author{
Daniel Ciolkosz \\ School of Bioresources Engineering and Environmental Hydrology, University of KwaZulu-Natal
}

\begin{abstract}
A methodology is presented for the correction and filling of solar radiation data at sites within South Africa, with the aim of creating a continuous, hourly-timestep dataset for multiple locations. Data from twenty sites, collected by the Agricultural Research Council, are analysed with regard to the amount of data requiring offset or multiplier adjustment, as well as the amount of bad data. A range correction algorithm is implemented based on the 90 th percentile (10\% exceedance) hourly irradiance, as a function of site latitude and elevation. The resulting, corrected data set is given the title: South African Solar Radiation Database (SAS$R A D)$. Comparisons are made with two other solar radiation datasets, the South African Atlas of Agrohydrology and Climatology, and a limited set of older historical data from the South African Weather Service (SAWS).

Results indicate that the SASRAD dataset matches well with other datasets, with major discrepancies apparently due to problems with the other data sets, rather than the SASRAD data. The Coefficient of Multiple Determination $\left(R^{2}\right)$ between the Atlas and $S A S R A D$ for monthly radiation is 0.927 , and the mean error between three of the SASRAD sites and the corresponding SAWS data is $1.1 \mathrm{MJ} \mathrm{m}^{-2} \mathrm{~d}^{-1}$. The fraction of data requiring correction varied from $11 \%$ to $100 \%$, depending on the site. The range correction algorithm was successful at correcting data that had been subject to incorrect calibration, and did not remove annual trends in mean radiation levels.
\end{abstract}

Keywords: solar radiation, South Africa, SASRAD, data sets

\section{Introduction}

Solar radiation is arguably the primary energy source for the earth, providing radiant and thermal energy to the earth's surface, wind energy through the creation of pressure gradients in the air, and chemical energy via the growth of photosynthetic organisms. Renewable energy technologies typically depend on the availability of solar radiation, either directly (i.e. photovoltaics or solar thermal systems) or indirectly (i.e. biofuels). The performance of these systems at a given location depends on the available insolation as well as other meteorological parameters (primarily temperature and wind), which can affect the performance of the energy utilization systems.

South Africa is fortunate to be located at a latitude and in a climate that is generally well suited for the utilization of solar energy. Early assessments of solar energy availability (i.e. Drummond \& Vowinckel, 1957; Schulze \& McGee, 1976), indicate that available insolation is as high as $29 \mathrm{MJ} \mathrm{m}^{-2}$ $\mathrm{d}-1$. Other more recent assessments of solar radiation in South Africa (i.e. Eberhard et al., 1990; Schulze et al., 1992) have confirmed this general finding. Power and Mills (2004) indicate that these values are not static over time, with global and diffuse irradiance at South African locations changing as much as 1.7 and $2.5 \%$ per decade. This suggests that information based on old historical records may not be as valuable as newer data.

Sources of solar radiation data typically report solar radiation values in terms of monthly averages, rather than short timestep values, and tend to provide generalized maps of the region, rather than data for discrete locations. Schulze et al., (1992) provide detailed maps of monthly solar radiation, using a temperature-based algorithm from Clemence (1992). It is important to note that monthly data, while useful for some applications, are not suitable for accurate modelling of solar-driven energy processes. Bekker (2007) found that using monthly average radiation values to model 
$\mathrm{PV}$ performance in South Africa introduced a mean error of $15.8 \%$ at 7 sites, when compared to short timestep (5 minute) values. Hourly radiation data was found to introduce a much smaller error (3.2\%).

The availability of solar radiation data in South Africa has been described as quite extensive, relative to other African nations (Bugaje, 2006). Surface meteorological measurements are carried out by several organizations, including the South African Weather Service and the Agricultural Research Council. At many sites, these automated measurements include readings of solar radiation, whose length of record varies from site to site. However, the accuracy of this data is also variable, as found by Bekker (2007). Their approach to the matter was to apply a multiplier to measured data from one site, based on a 30-day running average of data in Eberhard (1990). In addition to apparent multiplier errors, directly measured data often contain periods of bad or missing data. While some researchers have dealt with this problem by simulating irradiance based on other meteorological data (i.e. Maxwell, 1997), the required inputs for such models are not available at many sites.

Successful implementation of energy policies and programmes in South Africa depends on accurate assessment of renewable energy technologies. In turn, the accurate assessment of solar-based renewable energy technologies requires a reliable short-timestep database of radiation values. While measurements of solar radiation are carried out at several sites in South Africa, the reliability of this data is not sufficient for use in careful modelling and feasibility analyses. There is a need for a corrected dataset, ideally consisting of historical solar radiation data at many sites that spans a several-year period. The timestep would ideally be as small as 5minutes, although hourly data is probably sufficient, and comprise the typical timestep used for many solar radiation data sets (i.e. NREL, 1992). The duration of such a dataset would ideally be 30 years (Jagannathan et al., 1967), although some researchers have suggested that a shorter dataset is sufficient for reliable use (Castellvi \& Stöckle, 2001). The dataset should include simultaneous measurements of global horizontal and diffuse horizontal irradiance, as well as air temperature, windspeed and direction.

If such a dataset was available, it would be extremely useful for modelling of solar energy technologies, as well as other simulation tasks, such as building energy models and agricultural crop models. This paper reports on the generation and testing of such a database, which has been given the acronym SASRAD - South African Solar Radiation Database.

\section{Procedure}

\section{Source data - selection and inspection}

Hourly meteorological measurements were obtained from the Agricultural Research Council of

Table 1: Site locations and data period of sourcedata

\begin{tabular}{|c|c|c|c|c|c|c|}
\hline Site \# & Location & $\begin{array}{l}\text { Lat } \\
\text { (deg) }\end{array}$ & $\begin{array}{l}\text { Lon } \\
\text { (deg) }\end{array}$ & $\begin{array}{c}\text { Elev } \\
\text { (metres) }\end{array}$ & $\begin{array}{c}\text { Start of rec } \\
(y r)\end{array}$ & $\begin{array}{l}\text { th of record } \\
\text { (yrs) }\end{array}$ \\
\hline 30081 & Bonfoi Stellenbosch, WC & -33.936 & 18.782 & 292 & 1995 & 13 \\
\hline 30086 & Nietvoorbij Stellenbosch, WC & -33.917 & 18.860 & 149 & 1995 & 13 \\
\hline 30087 & Ugie, EC & -31.230 & 28.045 & 1537 & 1994 & 8 \\
\hline 30090 & Gullenberg, NP & -23.833 & 28.967 & 1100 & 1994 & 9 \\
\hline 30091 & Nondweni,,NP & -28.2 & 30.8 & 1100 & 1994 & 7 \\
\hline$\overline{30092}$ & Zaaiplaas Middelburg, MP & -25.75 & 29.9 & 1500 & 1994 & 7 \\
\hline 30093 & Pretoria Roodeplaat, GT & -25.604 & 28.354 & 1229 & 1999 & 9 \\
\hline 30105 & Rustenburg, NW & -25.724 & 27.291 & 1170 & 1997 & 11 \\
\hline 30113 & Hluhluwe, $\mathrm{KN}$ & -27.920 & 32.365 & 95 & 1999 & 9 \\
\hline 30142 & Vaalhartz, NC & -27.950 & 24.833 & 1169 & 1997 & 11 \\
\hline 30144 & Glen Bloemfontein, FS & -28.921 & 26.353 & 1344 & 1999 & 9 \\
\hline 30145 & Misgund Joubertina, EC & -33.765 & 23.492 & 737 & 1996 & 12 \\
\hline 30149 & Funeray, EC & -31.230 & 28.045 & -999 & 1995 & 13 \\
\hline 30160 & Ukulinga, KN & -29.667 & 30.4 & 775 & 1995 & 13 \\
\hline 30173 & Kakamas, NC & -28.788 & 20.655 & 667 & 1996 & 12 \\
\hline 30179 & Rietrivier PP, NC & -29.096 & 24.604 & 1140 & 1997 & 11 \\
\hline 30180 & Upington, $\mathrm{NC}$ & -28.464 & 21.205 & 793 & 1996 & 12 \\
\hline 30182 & Klaasvoogds Roberston, WC & -33.807 & 19.989 & 221 & 1996 & 12 \\
\hline 30187 & Vinkriver Robertson, WC & -33.756 & 19.776 & 259 & 1996 & 12 \\
\hline 30191 & Bloukranz Prieska, NC & -29.525 & 22.973 & 944 & 1996 & 11 \\
\hline
\end{tabular}


South Africa for twenty locations throughout the country. Available measurements included average hourly global horizontal irradiance, dry bulb temperature, relative humidity, windspeed and direction, and precipitation. The sites were chosen based on the maximum available length of record.

This data was reviewed for accuracy and completeness of data. The available length of the dataset varied from 7 years to 13 years. Visual inspection of the data indicated that many of the measurements were either missing or clearly incorrect, and would require careful correction if they were to be useful. Several categories of error were identified in the radiation data, as follows:

1. Missing data points - points at which no measurements were made, represented by -999 values in the dataset.

2. Single points out of range - single points at which the measured value is clearly out of range, relative to points before and after.

3. Periods in which data is out of range - sets of data in which the multiplier for the radiation sensor appears to have been incorrectly applied, resulting in measurements that are correct in form, but are erroneously high or low. This is presumably due to errors in the calibration of the sensors.

4. Data which show a steady increase or decrease with respect to time - occasionally, data was encountered where the measured irradiance value steadily increased or decreased from year to year. This is presumably due to sensor degradation or incorrect application of multipliers.

These errors were identified in each data set using the following approach:

- Step 1: Check data against expected minimum and maximum value ( 0.0 and $1450 \mathrm{~W} \mathrm{~m}-2)$. All points that fall outside these bounds are flagged as 'bad' points.

- Step 2: Check to ensure that nighttime irradiance values are zero, and daytime irradiance values are greater than zero. Data that does not meet this criterion are flagged as 'bad' points.
- Step 3: Manually examine data set for any additional bad points.

- Step 4: Manually inspect and identify points in which an offset or range error exists.

Steps 1 and 2 were automated as part of a computer program, while the $3 \mathrm{~d}$ and 4 th step required manual inspection of the data to identify anomalies.

\section{Data processing}

The observed errors in the dataset represent a rather formidable set of problems that require significant attention if the measurements are to be used with confidence. Therefore, a careful adjustment of all data was carried out according to the following procedure.

\section{Filling of bad data points}

All bad or missing data points were filled, based on the length of the period of the bad data, using the following approach, based on the procedure used in NREL (1992). This process was automated, using data processing routines written in the PVWave programming environment (VNI, 2005).

- Step 1: Sections of bad data which are less than or equal to 4 hours in duration were filled via linear interpolation, based on the values of the nearest good data points.

- Step 2: Sections of bad data whose duration ranges from 5 to $24 * 7$ hours in length were filled with corresponding points from the previous week, following week, previous year, or following year, depending on the availability of good data in that time period.

- Step 3: Sections of bad data whose duration is greater than $24 * 7$ hours were filled with corresponding data from the previous year, or the nearest year whose data is good.

\section{Offset adjustment}

Data which was in error by an offset value were identified by visually inspecting the dataset, and were corrected by adding or subtracting the appropriate value from the affected data.
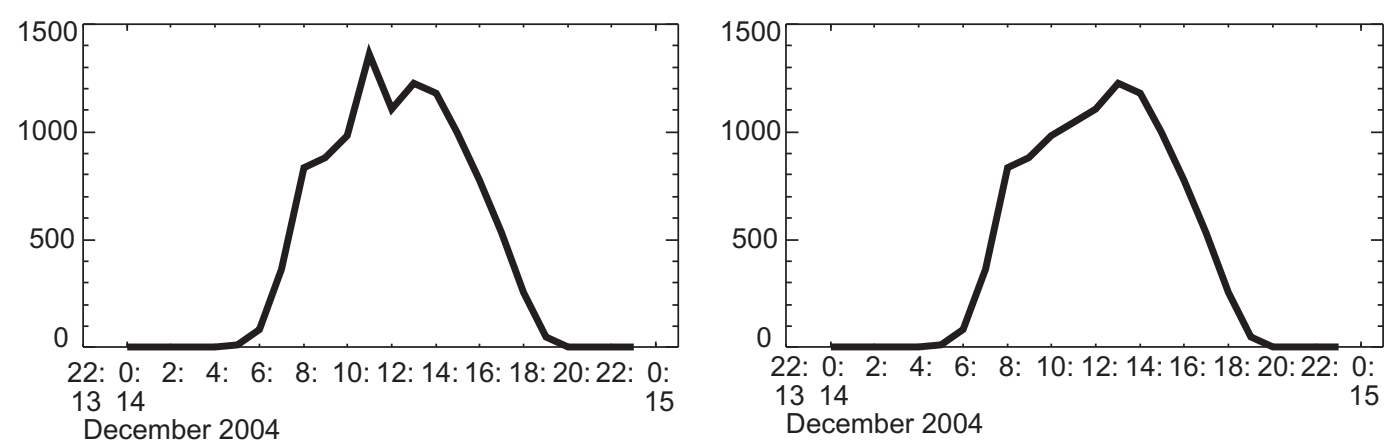

Figure 1: Sample data with single bad point, before and after fill operation (ARC Site 30081) 

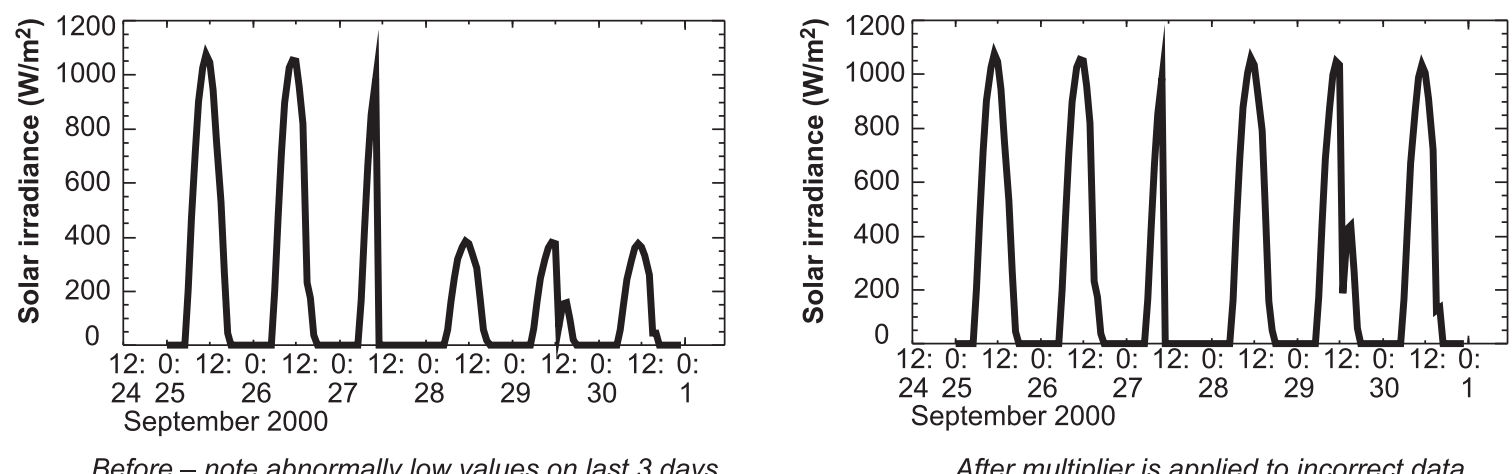

After multiplier is applied to incorrect data

Figure 2: Example of data before and after multiplier adjustment (Site \#30090)

Multiplier adjustment

Radiation data which was in error due to an incorrect multiplier were adjusted by multiplying those values by an appropriate correction factor. The correction factor was estimated manually and visually confirmed to ensure that the adjusted data match the adjacent, un-adjusted data (see Figure 2). Note that the data for half of the third day is missing, and as such were designated as 'bad points'.

After this 'course' adjustment was made, a more careful adjustment was carried out to ensure that the radiation data was adjusted correctly. This adjustment is based on the assertion that the maximum irradiance at a site will be a function only of site latitude and elevation. A polynomial function was created, based on the National Renewable Energy Laboratory National Solar Radiation Database (NSRDB) dataset for North America (NREL, 1992), which calculates the expected max- imum summer irradiance as a function of site latitude and elevation.

$$
\begin{aligned}
& \mathrm{E}_{\mathrm{DM}}=990.274+5.867 * \mathrm{~L}-0.14927 * \\
& \mathrm{~L}^{2}+0.033639 * \mathrm{E}
\end{aligned}
$$

Where

$\mathrm{E}_{\mathrm{DM}}=$ Maximum hourly irradiance at a site $(\mathrm{W}$ $\mathrm{m}^{-2}$, northern hemisphere)

$\mathrm{L} \quad=$ Site latitude (degrees)

$\mathrm{E} \quad=$ Site elevation (meters)

This function was then used to correct any datasets that are in error, based on the site's latitude and elevation. The function and the data from which the function are derived are shown in Figure 3. The $\mathrm{R}^{2}$ value for the equation is 0.947 .

Global horizontal radiation values in the dataset were corrected by applying a correction factor

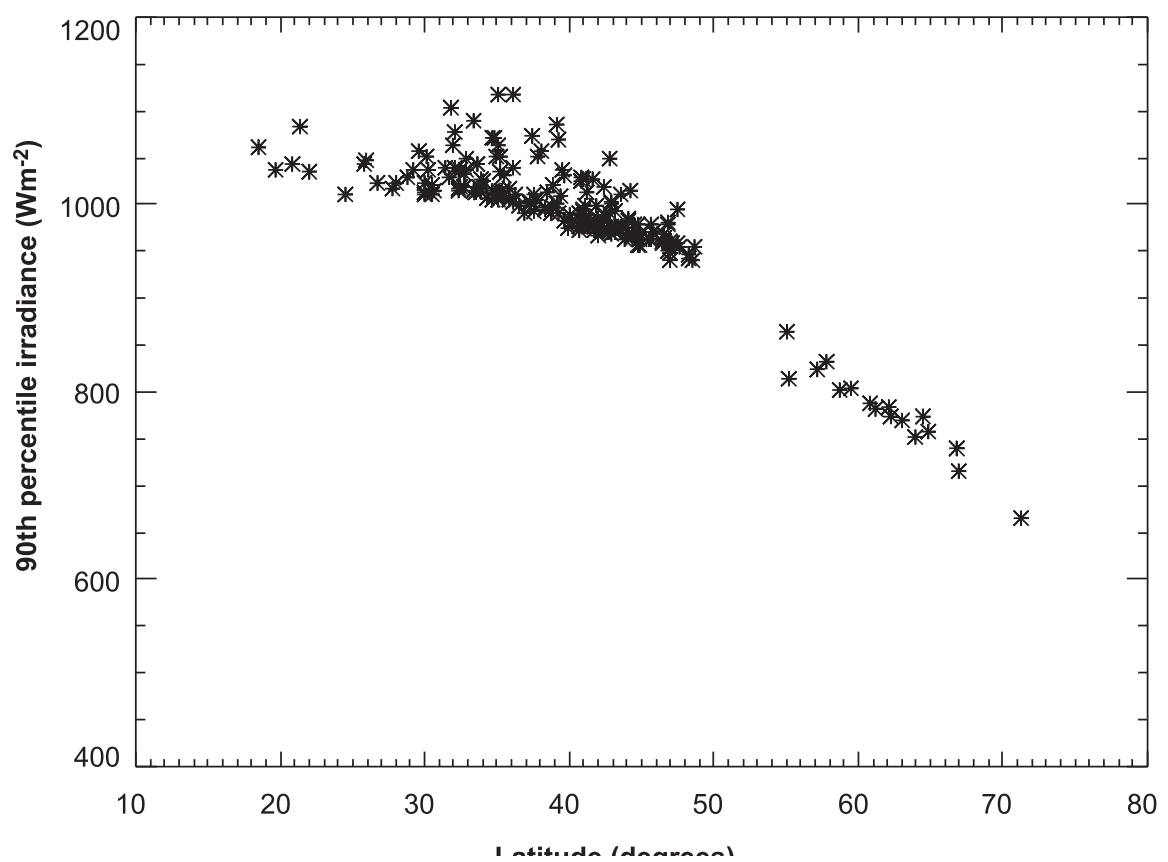

Figure 3: Summer maximum irradiance as a function of latitude 
based on the observed and expected maximum summer irradiance values.

$$
\mathrm{E}_{\mathrm{c}}=1.07 * \mathrm{E}_{\mathrm{m}} * \mathrm{E}_{\mathrm{cs}} / \mathrm{E}_{\mathrm{ms}}
$$

Where

$\mathrm{E}_{\mathrm{c}}=$ Corrected Irradiance Value $\left(\mathrm{W} \mathrm{m}^{-2}\right)$

$\mathrm{E}_{\mathrm{m}}=$ Uncorrected, Measured Irradiance $\left(\mathrm{W} \mathrm{m}^{-2}\right)$

$\mathrm{E}_{\mathrm{cs}}=$ 90th percentile (summer) irradiance, curve fit value $\left(\mathrm{W} \mathrm{m}^{-2}\right)$

$\mathrm{E}_{\mathrm{ms}}=$ 90th percentile (summer) irradiance, measured value $\left(\mathrm{W} \mathrm{m}^{-2}\right)$

The multiplier value of 1.07 is included to account for the fact that the sun is closer to the earth during the southern hemisphere summer, resulting in higher irradiance values than those in the northern hemisphere (i.e. Duffie \& Beckman, 1974). The 90th percentile was used rather than the absolute maximum in order to reduce the possible effect of outliers in the dataset. In the process of comparing the different percentiles, it was found that the R2 value for the polynomial equation was highest for the 90th percentile.

\section{Flagging of data}

In order to allow easy identification of the source of each data point, a 'flag' value was assigned to each value. The 'flag' values are integers that indicate the source and quality of that data point.

Table 2: Flag values for data points

\begin{tabular}{cl}
\hline Flag value & Meaning \\
\hline-9 & Data missing / not available \\
\hline-8 & Data bad - removed but not filled \\
\hline-5 & $\begin{array}{l}\text { Data modelled based on other } \\
\text { measurements }\end{array}$ \\
\hline-4 & Data adjusted by an offset \\
\hline-3 & Data adjusted by a multiplier \\
\hline-2 & Data filled from adjacent week \\
\hline-1 & Data filled from adjacent points \\
\hline 1 & Data not altered \\
\hline year (i.e. 2002) & Data filled from that year
\end{tabular}

\section{Addition of diffuse irradiance data}

The measured solar radiation data in this study consisted only of global horizontal irradiance values. Because of the importance of separating diffuse from total irradiance when simulating the performance of solar technologies, it was deemed necessary to include values of diffuse horizontal irradiance as well. These values were calculated (rather than being measured) using the procedure of Erbs et al. (1982) as outlined in Battles et al. (2000). Briefly, this consists of calculating the diffuse fraction based on the clearness index $(\mathrm{Kt})$ as follows:

$$
\begin{aligned}
& \mathrm{k}_{\mathrm{t}}=\mathrm{E}_{\mathrm{gh}} / \mathrm{E}_{\mathrm{xt}} \\
& \mathrm{E}_{\mathrm{gd}}=\mathrm{E}_{\mathrm{gh}} * \mathrm{~K} \\
& \mathrm{~K}=1.0-0.09 \mathrm{k} \quad \text { when } \mathrm{k}_{\mathrm{t}}<0.22 \\
& \mathrm{~K}=0.9511-0.1604 \mathrm{k}_{\mathrm{t}}+4.388 \mathrm{k}_{\mathrm{t}}^{2}- \\
& 16.638 \mathrm{k}_{\mathrm{t}}^{3}+12.336 \mathrm{k}_{\mathrm{t}}^{4} \\
& \text { when } 0.22<\mathrm{kt}<0.8
\end{aligned}
$$$$
\mathrm{K}=0.165 \quad \text { when } \mathrm{k}_{\mathrm{t}}>0.8
$$

Where

$\mathrm{K}_{\mathrm{t}}=$ Clearness index, dimensionless

$\mathrm{E}_{\mathrm{gh}}=$ Global horizontal irradiance, $\mathrm{w} \mathrm{m}^{-2}$

$E_{\mathrm{xh}}=$ Extra terrestrial horizontal irradiance, $\mathrm{w} \mathrm{m}^{-2}$

$E_{\mathrm{gd}}=$ Global diffuse irradiance, $\mathrm{w} \mathrm{m}^{-2}$

$\mathrm{K}$ = diffuse fraction, dimensionless

Similar data review and correction procedures were carried out on the other meteorological data (temperature, humidity, wind and precipitation) full details can be found in Ciolkosz (2008).

\section{Testing of data}

Since the only comparable data available is aggregated daily or monthly, the data in this study was tested by calculating monthly values and comparing them to those reported in the South African Atlas of Hydrology and Agroclimatology (Schulze et al., 1997). This source was chosen because of its representation of solar radiation at all locations within South Africa, as well as its thorough presentation of temperature and humidity data. The monthly mean daily radiation for each site was calculated both from the SASRAD dataset and from the information in the atlas, and the values were compared by calculating the mean difference and $\mathrm{R}^{2}$ for the data.

\section{File format}

Data is saved in a series of formatted ASCII text files, with separate files for each location and year of data. The file name is formatted as follows: SSSSS_YYYY.srd where SSSSS = site number, and YYYY = year of data. The first line of data in each file is a header, containing site information. Subsequent lines consist of hourly readings - one line for each hour of the year. The format of the file is as in Tables 3 and 4.

\section{Results}

Visual inspection of the datasets indicated values that appear reasonable in magnitude for the locations in question. The fraction of radiation data which required some sort of adjustment varied from $11.1 \%$ to $100 \%$, as per Table 5. Information on the correction of the other meteorological data can be found in Ciolkosz (2008).

Global horizontal irradiance values for all sites 
Table 3: Header format

\begin{tabular}{lcl}
\hline Position & Name & \\
\hline $1-5$ & Site Code & as given by ARC \\
\hline $7-30$ & City & or town or farm name \\
\hline $32-33$ & Province & EC = Eastern Cape, FS = Free State, GT = Gauteng, KN = KwaZulu-Natal \\
& & LP = Limpopo, MP = Mapumalanga, NC = Northern Cape, NW = Northwest Province, \\
& & $\mathrm{C}=$ Western Cape \\
\hline $35-39$ & Latitude & decimal degrees \\
\hline $41-45$ & Longitude & decimal degrees \\
\hline $47-50$ & Elevation & meters above sea level \\
\hline 52 & Source & 'A' = ARC \\
\hline $54-55$ & Version & O1 = first release, 2007, 02 = current release (2008) \\
\hline
\end{tabular}

Table 4: Format of data lines

\begin{tabular}{llc}
\hline Position & Name & Units \\
\hline $1-4$ & Year & AD \\
\hline $6-7$ & Month & $1-12$ \\
\hline $9-10$ & Day & $1-31$ \\
\hline $12-13$ & Hour & $0-23$ \\
\hline $15-18$ & Global Horizontal Radiation & $\mathrm{W} \mathrm{m}^{-2}$ \\
\hline $20-23$ & Radiation Flag & see Table 2 \\
\hline $25-28$ & Diffuse Horizontal Radiation & $\mathrm{W} \mathrm{m}^{-2}$ \\
\hline $30-33$ & Diffuse Radiation Flag & see Table 2 \\
\hline $35-39$ & Dry Bulb Temperature & ${ }^{\circ} \mathrm{C}$ \\
\hline $41-44$ & Temperature Flag & see Table 2 \\
\hline $46-49$ & Relative Humidity & Percent \\
\hline $51-54$ & Humidity Flag & see Table 2 \\
\hline $56-59$ & Windspeed & $\mathrm{m} \mathrm{s}^{-1}$ \\
\hline $61-64$ & Windspeed Flag & see Table 2 \\
\hline $66-69$ & Wind Direction & Degrees \\
\hline $71-74$ & Wind Direction Flag & see Table 2 \\
\hline $76-79$ & Precipitation & mm hr ${ }^{-1}$ \\
\hline $81-84$ & Precip Flag & see Table 2 \\
\hline
\end{tabular}

Table 6: Sample data file

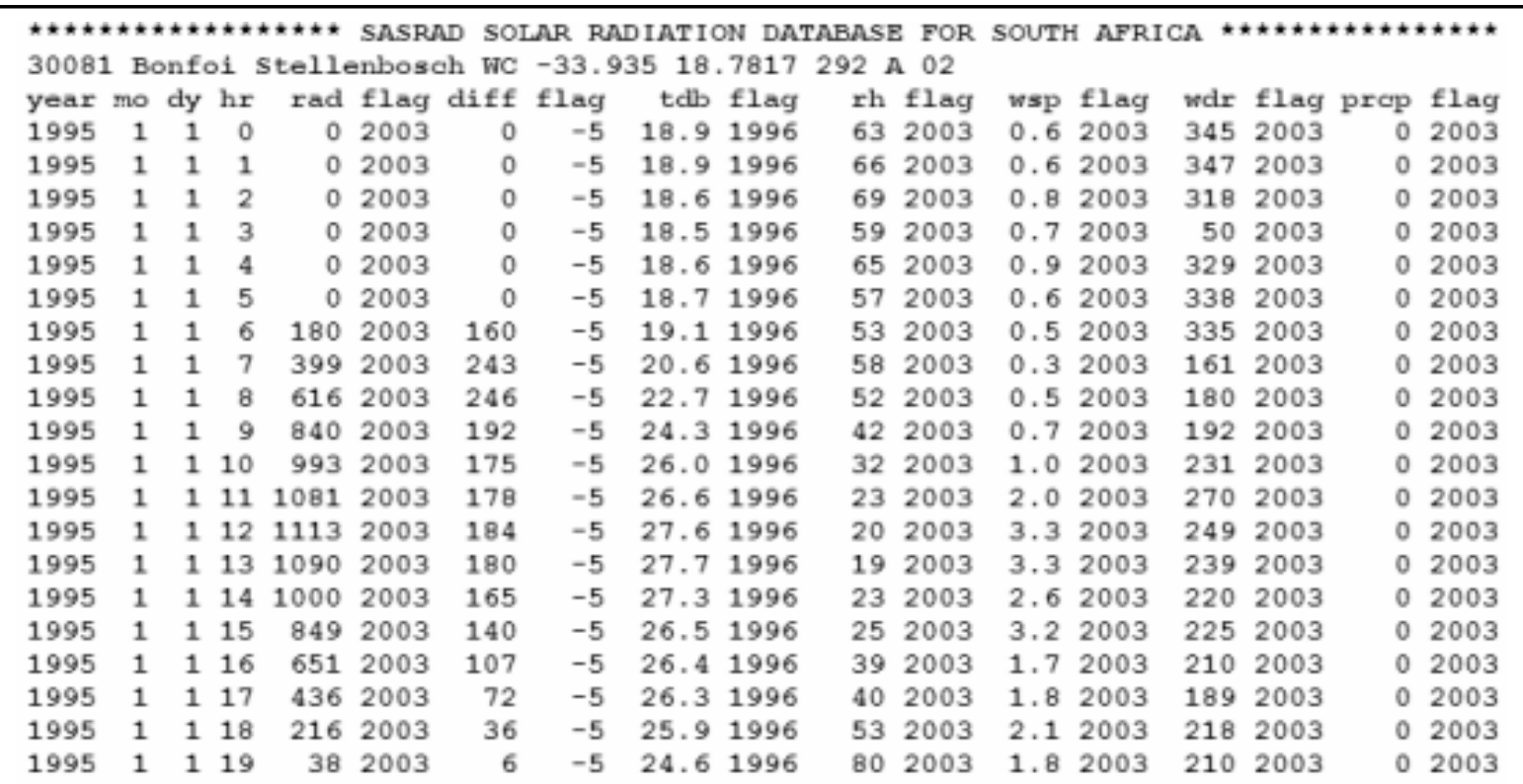


Table 5: Summary of radiation data correction

\begin{tabular}{llccccc}
\hline Site \# & Location & $\begin{array}{c}\text { Length of } \\
\text { record (yrs) }\end{array}$ & \% good & \% filled & \% mult & \% bad \\
\hline 30081 & Bonfoi Stellenbosch, WC & 13 & 13.8 & 69.9 & 16.3 & 0 \\
\hline 30086 & Nietvoorbij Stellenbosch, WC & 13 & 63.3 & 9.7 & 27.0 & 0 \\
\hline 30087 & Ugie, EC & 8 & 0 & 79.0 & 21.0 & 0.0014 \\
\hline 30090 & Gullenberg, NP & 9 & 40.7 & 26.6 & 32.7 & 0 \\
\hline 30091 & Nondweni,,NP & 7 & 42.8 & 50.1 & 7.1 & 0 \\
\hline 30092 & Zaaiplaas Middelburg & 7 & 82.3 & 17.7 & 0 & 0 \\
\hline 30093 & Pretoria Roodeplaat, GT & 9 & 79.1 & 19.3 & 1.6 & 0 \\
\hline 30105 & Rustenburg, NW & 11 & 83.8 & 16.2 & 0 & 0 \\
\hline 30113 & Hluhluwe, KN & 9 & 88.9 & 11.1 & 0 & 0 \\
\hline 30142 & Vaalhartz, NC & 11 & 36.4 & 9.7 & 53.9 & 0 \\
\hline 30144 & Glen Bloemfontein, FS & 9 & 83.7 & 16.0 & 0.3 & 0 \\
\hline 30145 & Misgund Joubertina, EC & 12 & 73.9 & 11.0 & 15.1 & 0 \\
\hline 30149 & Funeray, EC & 13 & 22.7 & 55.4 & 21.9 & 0.0008 \\
\hline 30160 & Ukulinga, KN & 13 & 40.1 & 48.7 & 11.2 & 0 \\
\hline 30173 & Kakamas, NC & 12 & 86.7 & 13.3 & 0 & 0 \\
\hline 30179 & Rietrivier PP, NC & 11 & 65.9 & 19.9 & 14.2 & 0 \\
\hline 30180 & Upington, NC & 12 & 41.5 & 11.6 & 46.9 & 0 \\
\hline 30182 & Klaasvoogds Roberston, WC & 12 & 29.1 & 17.4 & 53.5 & 0 \\
\hline 30187 & Vinkriver Robertson, WC & 12 & 76.2 & 22.4 & 1.4 & 0 \\
\hline 30191 & Bloukranz Prieska, NC & 11 & 0 & 21.6 & 78.4 & 0 \\
\hline
\end{tabular}

Table 7: Annual trends in daily radiation

\begin{tabular}{ll} 
Site no. & $\begin{array}{c}\text { Annual trend } \\
\left(\mathrm{MJ} \mathrm{m}^{-2} \mathrm{~d}^{-1} \text { per year }\right)\end{array}$ \\
\hline 30081 & 0.0155 \\
\hline 30086 & -0.0224 \\
\hline 30087 & -0.0473 \\
\hline 30090 & -0.0289 \\
\hline 30091 & -0.0329 \\
\hline 30092 & -0.0426 \\
\hline 30093 & 0.1735 \\
\hline 30105 & 0.0603 \\
\hline 30113 & -0.0056 \\
\hline 30142 & 0.0651 \\
\hline 30144 & 0.1847 \\
\hline 30145 & 0.0378 \\
\hline 30149 & 0.1141 \\
\hline 30160 & 0.0550 \\
\hline 30173 & 0.0066 \\
\hline 30179 & -0.0086 \\
\hline 30180 & 0.0581 \\
\hline 30182 & 0.1055 \\
\hline 30187 & 0.0846 \\
\hline 30191 & -0.0382 \\
\hline average & 0.0367 \\
\hline
\end{tabular}

and times averaged $235.1 \mathrm{w} \mathrm{m}-2$, which corresponds to $20.3 \mathrm{MJ} \mathrm{m}-2 \mathrm{~d}-1$. A sample of a SASRAD data file is shown in Table 6.

\section{Annual trends}

Annual trends in the SASRAD data are summarised in Table 7. Of the 20 sites, 11 show an increase in solar radiation, with 9 showing a decrease. The maximum increase is for site 30144 (Glen Bloemfontein), and the greatest decrease is at site 30087 (Ugie). On average, the solar radiation data are increasing in magnitude at an annual rate of $0.037 \mathrm{MJ} \mathrm{m}^{-2} \mathrm{~d}^{-1}$.

Sample plots are given in Figure 4 for two representative sites, showing the variation in daily radiation from year to year. While an overall trend is apparent, the variation from year to year is quite noticeable as well.

\section{Comparison to other datasets}

Comparison of the mean of the monthly radiation data from the SASRAD dataset to the South African Atlas of Hydrology and Agro-Climatology (Schulze et al., 1997) showed good agreement, with an $\mathrm{R}^{2}$ of 0.927. The mean difference between the two datasets is $3.72 \mathrm{MJ} \mathrm{m}^{-2} \mathrm{~d}^{-1}$. Typically, the two datasets agree most closely at midwinter, with SAS$\mathrm{RAD}$ giving lower values during summer months (see Figure 6). This discrepancy is most likely due to problems with the radiation-prediction algorithm 

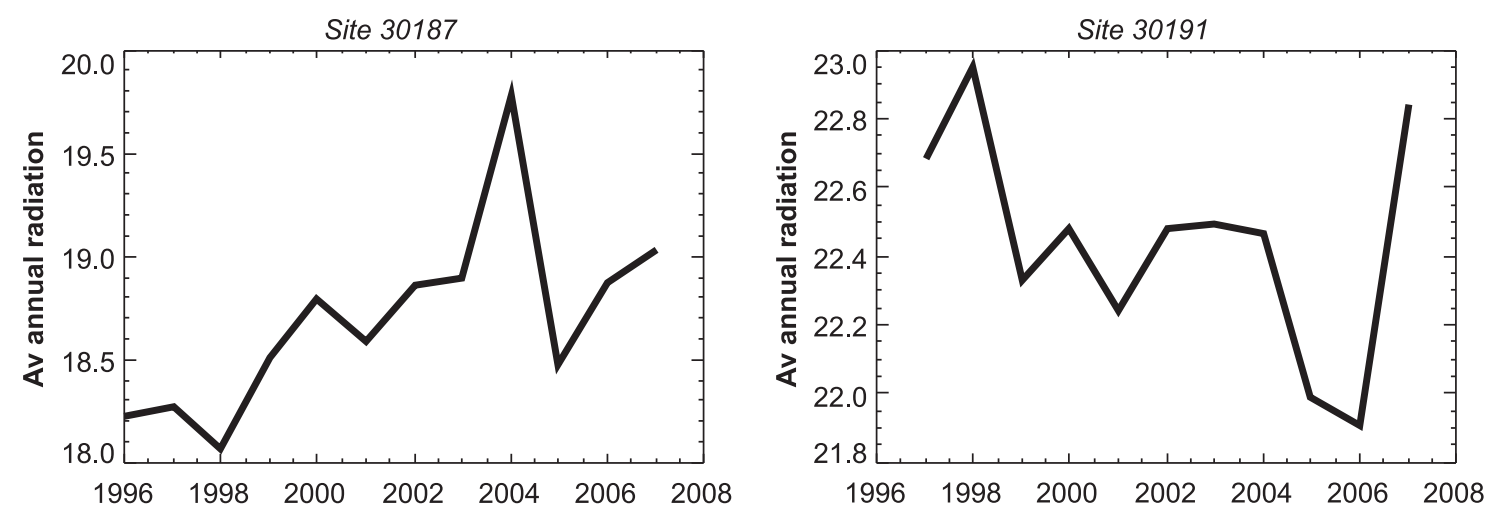

Figure 4: Annual variation in daily radiation for two sites $\left(\mathrm{MJ} \mathrm{m}^{-2} \mathrm{~d}^{-1}\right)$

used in the atlas, as the algorithm is best suited only for clear sky conditions, and is not as accurate under the cloudy conditions typically found in summer months over most of South Africa (Horan, 2008).

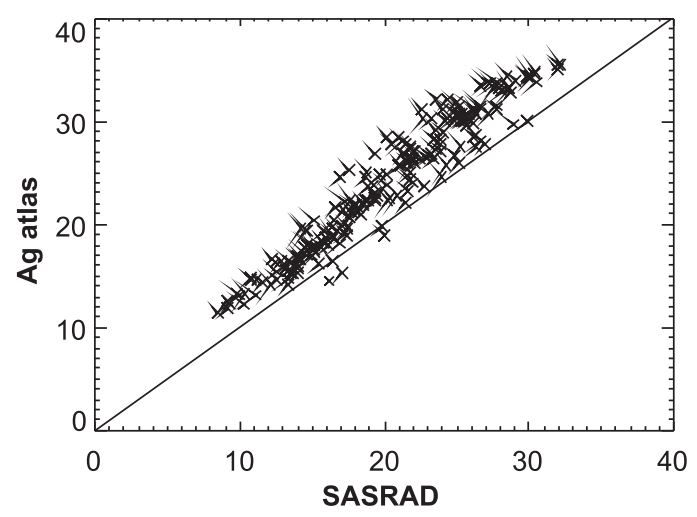

Figure 5: SASRAD vs. Ag Atlas daily radiation (MJ m ${ }^{-2} \mathrm{~d}^{-1}$ )

Comparison of the SASRAD data for three sites (Upington, Glen, and Pretoria) to a rather old set of South African Weather Service data for nearby locations (1957-1997) indicates a much closer agreement to the SASRAD data than to those from the Ag Atlas (results not shown). Therefore, the differences between SASRAD and the Ag Atlas do not appear to be indicative of any systematic error in the SASRAD data. Note that revisions are underway for the next release of the atlas, in which these deficiencies are corrected (Horan, 2008).

\section{Discussion}

The SASRAD database presented here represents a consistent, continuous set of hourly radiation data for multiple sites in South Africa that can be used for evaluation of a variety of solar technologies. The locations of the 20 sites were chosen as a function of the available data records, and as such do not cover all areas in South Africa. As the data originates from the Agricultural Research Council, the sites are also generally not within the major population centres of South Africa. Coincident values for temperature, humidity, wind speed and precipitation are also provided, which makes the data set especially valuable for modelling purposes.

The correction procedures applied to the data are quite extensive, but the resulting values appear to correlate well to existing aggregated data, with any discrepancies accountable to problems with the reference data set, rather than the SASRAD data. As with any data set, the major concern is for the
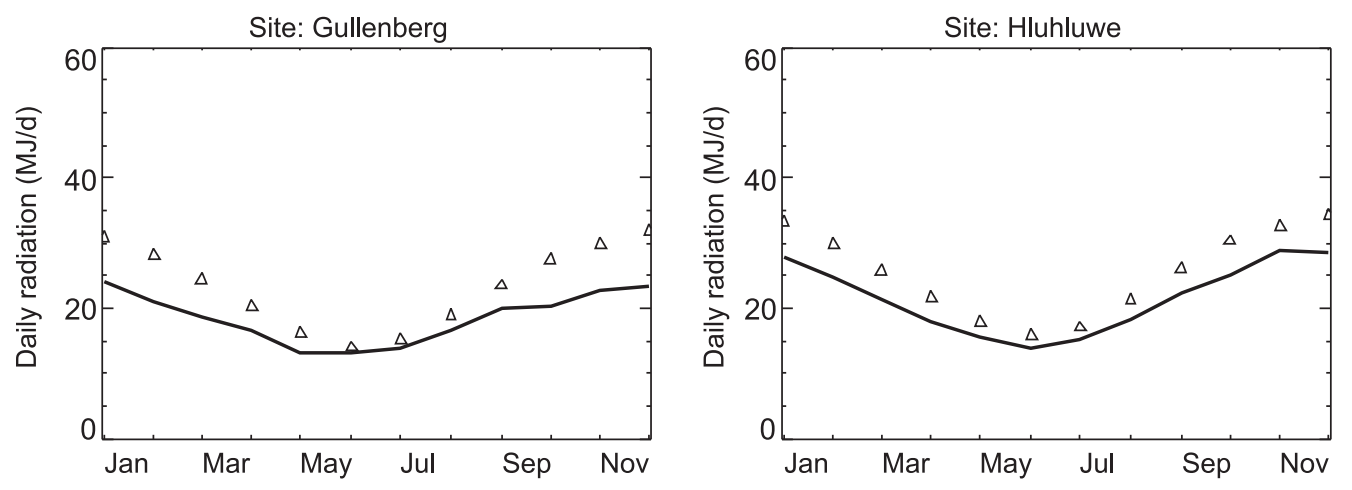

Figure 6: Annual Variation in SASRAD and Ag Atlas daily radiation for two typical sites $\left(\mathrm{MJ} \mathrm{m}^{-2} \mathrm{~d}^{-1}\right)$ 
accuracy of the data. While it is not possible to rigorously test the SASRAD data on an hour-by-hour basis, the results presented here suggest that the corrected SASRAD dataset can be used with good confidence.

The range correction appears to be successful at correcting the radiation values without 'erasing' any year-to-year differences, as the annual trends are of the same magnitude as those reported in Power and Mills (2004). However, annual trends are not expected to be accurate at locations in which extensive data filling was utilised. The range correction algorithm is a vital step in the processing of the data, as without it the radiation data would not be expected to exhibit reliable values from year to year. Corrections based on the average radiation value (rather than the maximum) are less valuable for this purpose, as they would tend to normalise radiation values to an overall mean, which should be expected to vary from year to year, due to long term trends in climate (principally cloud cover).

The range correction algorithm does not make allowances for annual variation in sky clearness, as could be caused by large volcanic eruptions, such as the Mt. Pinatubo eruption in 1992 (Power \& Mills, 2004). However, the period in which the dataset was collected was not subjected to largescale volcanic activity. If need be, a correction factor could be applied to data in future years if this becomes an issue.

Future enhancements to the SASRAD database could include inclusion of additional sites, expansion of the length of data record, and further refinement to the data correction algorithm. Originally, the SASRAD database was intended for the investigation of energy and environmental performance of agricultural and rural structures, hence the use of the ARC dataset with its focus on rural locations. However, the potential uses for this dataset are much broader, including the modelling of solar energy technologies, modelling of building performance, development of engineering design data, and creation of 'typical year' climate files. Many of these tasks have already been carried out for some sites by others, but the SASRAD dataset affords the opportunity to extend these efforts to a wider array of locations within South Africa.

\section{Conclusions}

The following conclusions can be drawn from the generation and testing of the SASRAD data set.

- A significant degree of correction and filling of data is required in order to render useful the currently available measured radiation data for South Africa.

- The use of automated and manual identification of bad data, coupled with a range correction algorithm, results in radiation data that agrees with earlier datasets for the region.
- The range correction algorithm is successful at normalizing the radiation data without removing annual trends in radiation values.

\section{Acknowledgements}

Thanks are extended to the Agricultural Research Council of South Africa, including Irene van Gent, Gert de Nysschen, and Maureen Fritz. This project was made possible by the University of KwaZulu-Natal (UKZN) competitive grant \#5163. Special thanks also go to Mark Horan of UKZN for his support and insight.

\section{References}

Battles, F. J., Rubio, M. A., Tovar, J., Olmo, F. J., and Alados-Arboledas, L. 2000. Empirical Modelling of Hourly Direct Irradiance by Means of Hourly Global Irradiance. Energy 25:675-688.

Bekker, B. 2007. Irradiation and PV Array Output, Cost and Optimal Positioning for South Africa. Journal of Energy in Southern Africa. 18(2).

Bugaje, I. M. 2006. Renewable energy for sustainable development in Africa: a review. Renewable and Sustainable Energy Reviews. 10(6):603-612.

Castellvi, F., and Stöckle, C.O. 2001. Comparing the performance of WGEN and ClimGen in the generation of temperature and solar radiation. Transactions of the ASAE Vol. 44(6): 1683-1687. American Society of Agricultural Engineers St Joseph, MI.

Ciolkosz, D. 2008. The South African Solar Radiation Database (version 2, 2008). Project Report. University of KwaZulu-Natal School of Bioresources Engineering and Environmental Hydrology. Scottsville, South Africa.

Clemence, B. S. E. 1992. An Attempt at Estimating Solar Radiation at South African Sites Which Measure Air Temperature Only. South African Journal of Plant and Soil, 9, 40-42.

Drummond, A. J., and Vowinckel, E. 1957. The Distribution of Solar Radiation throughout Southern Africa. Journal of Meteorology. 14:343-353.

Duffie, J. A. and Beckman W. A. 1974. Solar Energy Thermal Processes. John Wiley and Sons. New York.

Eberhard, A. 1990. A Solar Radiation Data Handbook for Southern Africa. Elan Press. Cape Town (1990).

Erbs, D. G., Klein, S. A., and Duffie, J. A. 1982. Estimation of the diffuse radiation fraction for hourly, daily and monthly-average global radiation. Solar Energy 28:293-302.

Grobler, L. J. and W.I.R den Heijer. 2000. Development of Heating- and Cooling Degree-day data for South African Locations. Journal of Energy in Southern Africa. 11(3).

Horan, M. 2008. Personal Communication. University of KwaZulu-Natal School of Bioresources Engineering and Environmental Hydrology.

Jagannathan, P.R., R. Arlery, and H. T. Kate, and Zavarina, M. V. 1967. A Note on Climatological 
Normals. Technical Note 87. World Meteorological Organisation. Geneva, Switzerland.

Maxwell, E. L. 1987. A Quasi-Physical Model for Converting Hourly Global to Direct Normal Insolation. SERI/TR-215-3087.

Maxwell, E. L. 1997. Metstat - the Solar Radiation Model Used in the Production of the National Solar Radiation Database (NSRDB). Solar Energy 62(4):263-279.

NREL. 1992. User's Manual - National Solar Radiation Data Base (1961 - 1990), Version 1.0. NSRDB Vol. 1, 93pp.

Power, H. C., and Mills, D. M. 2004. Trends in Solar Radiation over South Africa and Namibia during the Period 1957 - 1997. Presented at American Geophysical Union Spring Meeting 2004.

Schulze, R E. and McGee, O. S. 1976. Winter and Summer Insolation Patterns for Southern Africa. South African Journal of Science. 72: 182-183.

Schulze, R. E., Maharaj, M., Lynch, S. D., Howe, B. J., and Thompson, B. M. 1997. South African Atlas of Agrohydrology and Climatology. Water Research Commission. Pretoria, South Africa. Report TT82/96.

VNI. 2005. PV-Wave. Ver. 8.01. Houston, TX. Visual Numerics, Inc.

Received 2 June 2008; revised 9 February 2009 